\title{
Irrigação localizada subsuperfical: Gotejador convencional e novo protótipo ${ }^{1}$
}

\begin{abstract}
Wanderley de J. Souza ${ }^{2}$, Tarlei A. Botrel ${ }^{2}$, Rubens D. Coelho ${ }^{2}$ \& Nilson A. V. Nova ${ }^{2}$
RESUMO

A irrigação por gotejamento subsuperficial, que utiliza um sistema protetor do emissor para evitar entupimento do mesmo por raiz e partículas sólida do solo, pode ser viável em relação a um sistema convencional. Propôs-se, com este trabalho, avaliar o desempenho de um sistema para proteção de emissor e comparar os resultados com um sistema que utiliza emissor convencional para irrigação por gotejamento subsuperficial. O sistema com protetor foi construído com materiais de baixo custo: mangueira de polietileno, microtubo, conector e um gotejador para controlar a vazão e no sistema convencional utilizou-se um emissor comercial. Após 12 meses de avaliação o sistema com protetor demonstrou bom desempenho com vazão relativa média de 0,97 e 0,98 em vasos com e sem cultura, respectivamente, não apresentando problemas de entupimento e tendo menor custo. No sistema convencional constatou-se vazão relativa de 0,51 e 0,98 em vasos com e sem cultura, respectivamente, grau de entupimento por raiz de $49,22 \%$ e emissores com solo em seu interior. Desta forma, o uso do emissor com sistema de proteção indicou viabilidade para irrigação subsuperficial por gotejamento, nas condições desta pesquisa.
\end{abstract}

Palavras-chave: intrusão radicular, entupimento, sucção de partículas sólidas

\section{Subsurface drip irrigation: Conventional dripper and new prototype}

\begin{abstract}
Subsurface drip irrigation that uses an emitter protection system to avoid its clogging by roots and soil particles may be viable compared to a conventional system. The objective of this work was to evaluate the performance of a system with emitter protection, and to compare the results with a system that uses a conventional emitter for subsurface drip irrigation. In the system with protection an inexpensive materials polyethylene hose, microtube, connector, and a dripper to control the flow rate were used; and, in the conventional system a commercial emitter was used. After 12 months of evaluation, the system with protector showed good performance, with relative average flow rate of 0.97 and 0.98 in pots with and without crop, respectively, showing no clogging problems and lower cost. In conventional system relative flow rate of 0.51 and 0.98 were observed in pots with and without crop, respectively, also clogging degree by roots of $49.22 \%$, and emitters with soil inside was observed. Thus, the use of emitter with protection presented feasibility for subsurface drip irrigation, under conditions used in this research.
\end{abstract}

Key words: root intrusion, clogging, suction of solid particles

Parte da Tese de Doutorado do primeiro autor apresentada ao curso de Pós-graduação em Irrigação \& Drenagem, ESALQ/USP; Projeto financiado pela FAPESP

2 ESALQ/USP. Av. Pádua Dias 11, C.P. 9, CEP 13418-900. Piracicaba, SP. Fone: (19) 3447-8549. E-mail: wjsouza@esalq.usp.br; tabotrel@esalq.usp.br; rdcoelho@esalq.usp.br; navnova@esalq.usp.br 


\section{INTRODUÇÃO}

A irrigação por gotejamento subsuperficial (SDI) deriva do gotejamento superficial, sendo constituída por emissores instalados na subsuperfície do solo, com aplicação da água na zona radicular da cultura. A primeira instalação de SDI ocorreu na década de 60, em Israel (Marques et al., 2006) e tem sido utilizada nos Estados Unidos nos últimos 40 anos, por ser adequada para a maioria das culturas, em particular para frutas e vegetais de alto valor, tal como para paisagismo (Suarez-Rey et al., 2006). No Brasil, o uso desta tecnologia na cultura da cana-de-açúcar vem sendo avaliado principalmente em relação ao incremento na produtividade; entretanto, o entupimento por raiz e partículas sólidas do solo constitui um entrave, caso em que um sistema protetor do emissor de água pode ser útil para implantação em jardins e culturas arbóreas mesmo que não possa ser utilizado em pequenas áreas com outras culturas.

O sistema possibilita provimento de água às culturas pela aplicação de baixo volume, reduzindo as perdas hídricas nos sistemas de cultivo (Parkes et al., 2010), enquanto uma porção superficial do solo é mantida relativamente seca. Em locais onde ocorre alto consumo hídrico pelas culturas e a irrigação é indispensável, como em regiões áridas e semiáridas, recomendase o uso de SDI (Tabatabaei \& Najafi, 2007) em virtude de utilizar: menor quantidade de água devido à menor taxa evaporativa; segurança do sistema de irrigação, com redução dos danos mecânicos; utilização do mesmo sistema para diferentes culturas (Rajput \& Patel, 2009); aumento de produtividade (Singh et al., 2006) e de não necessitar remover o sistema de irrigação na operação de colheita, como ocorre no cultivo da cana-de-açúcar. Além do mais, a água pode ser aplicada uniformemente com alta frequência em relação à irrigação por aspersão e sulco; entretanto, este potencial é tecnológico e depende do projeto, instalação, operação e manutenção (May \& Hanson, 2007).

O controle de qualidade na fabricação dos emissores é primordial visto que suas vazões podem ser inconstantes, em lotes com coeficiente de variação de fabricação alto, não obstante isto possa ocorrer também em sistema superficial. A manutenção no subsolo é mais difícil; a taxa de vazão de cada emissor pode ser afetada pelas propriedades do solo (Gil et al., 2008), além da possibilidade de entupimento por partículas sólidas e raízes. Esses dois últimos são os principais problemas operacionais que devem ser confrontados uma vez que as propriedades do solo não analisadas no dimensionamento hidráulico, partículas biológicas como algas e lodo de bactéria, são eliminadas pela injeção de cloro (Resende et al., 2004); precipitação química pode ser evitada pela aplicação de ácidos e controle do $\mathrm{pH}$ enquanto sólidos suspensos podem ser evitados com sistemas de filtragem adequados. Em pesquisas realizadas com entupimentos decorrentes de partículas sólidas na malha hidráulica, Coelho et al. (2007) observaram que a obstrução total foi predominante em relação à parcial (afeta uma porção dos emissores igualmente).

$\mathrm{O}$ entupimento causado por partículas e/ou algas e bactérias, provenientes da água de irrigação, geralmente ocorre nas extremidades da linha lateral, sendo a limpeza no final da linha a técnica mais recomendada. Por outro lado, entupimentos ocasionados por intrusão radicular e partículas sólidas do solo, podem ocorrer de maneira geral, comprometendo todo o sistema de irrigação pelo aumento do grau de entupimento e redução da vazão relativa dos emissores. O problema de sucção de partículas sólidas vem sendo estudado em algumas instituições, dentre outras UNICAMP, UNESPe ESALQ, tendo-se sugerido duas formas de evitá-lo: uso de válvulas antivácuo nas tubulações e gotejadores com dispositivo antissucção. Ambos os métodos acrescentam custos na aquisição dos emissores.

O entupimento dos emissores por raiz e partículas sólidas do solo constitui uma ameaça para o sucesso dos sistemas em longo prazo, podendo ser mais agravante quando se utiliza SDI em culturas de raízes fibrosas (Suarez-Rey et al., 2006). A prevenção da intrusão de raízes pode ser obtida com a aplicação de produtos químicos ou pela utilização de emissores projetados para oferecer uma barreira física à intrusão. O primeiro caso já existe, devendo ser avaliadas a eficiência em diversas culturas a longo prazo e as formas de reduzir o custo de aquisição. Em um experimento no Sul do Arizona, Cloi \& SuarezRey (2004) encontraram intrusão radicular em alguns emissores após um ano de pesquisa com "grama" Bermuda, na qual os autores injetaram ácido sulfúrico em água sob $\mathrm{pH}$ abaixo de 6,5. O uso de barreira física também vem sendo avaliado por alguns autores, dentre outros Mosca et al. (2005), constituindo ainda um fator que merece alto grau de estudo, devendo ser pesquisados emissores com tal mecanismo e que apresente baixo custo. Neste caso, a seleção técnico-econômica se baseia nas características de funcionamento e custos do emissor, sendo a alternativa mais adequada aquela de menor custo e melhor desempenho técnico (Holzapfel et al., 2007).

O fato do entupimento por intrusão radicular e partículas sólidas do solo em gotejadores ser irreversível, motivou a realização desta pesquisa buscando reduzir tal problema, utilizando um sistema para proteção do emissor, proposto com base em suas características construtivas, de forma que se garanta a vazão de projeto em sistemas de irrigação subsuperficial localizada.

\section{Material E MÉTODOS}

Para esta pesquisa foram utilizados um sistema protetor de emissor (A) e um emissor (B) convencional utilizado em irrigação subsuperficial por gotejamento. As avaliações e o desenvolvimento foram realizados no Departamento de Engenharia de Biossistemas da ESALQ/USP, sendo o sistema com o modelo "A" construído no laboratório de hidráulica; ambos os sistemas foram avaliados em casa de vegetação, em vasos, quanto a entupimento por raiz e partículas sólidas do solo.

Para concepção deste sistema utilizaram-se mangueira de polietileno na composição do tubo protetor e microtubo, que são materiais de baixo custo. O sistema é caracterizado como estrutura de proteção contra entrada de raízes e partículas sólidas do solo em mangueira de irrigação por gotejamento subsuperficial. O modelo consiste em uma adaptação do tubo protetor ao microtubo/mangueira de polietileno, para proteção do orifício de saída de água do emissor, ligados a um gotejador para controlar a vazão. A água é aplicada no solo por meio de 
um microtubo que faz a ligação entre um gotejador inserido na linha lateral e um tubo que pode ser de PVC ou polietileno, ou outro material de baixo custo, cortado em comprimento suficiente para manter a extremidade do microtubo livre de solo e água. A água infiltrada no solo é absorvida pelas raízes que permanecem no exterior do tubo, uma vez que dentro dele não existam solo, nutrientes nem água, condições favoráveis para o desenvolvimento de raízes, o que constitui uma barreira que impede a penetração de raiz e sucção de partículas sólidas para dentro do emissor e mangueira de irrigação. Caso ocorra entrada de raízes e/ou partículas sólidas de solo, haverá entupimento, o que pode ser analisado medindo-se a vazão e/ ou desenterrando o sistema.

Na Figura 1 apresenta-se um desenho hipotético do sistema "A" com protetor do emissor. Neste caso, poderia ser utilizado apenas um microtubo de pequeno diâmetro como emissor, para controle da vazão a aplicar, sendo mais vantajoso em termos de custo, com possibilidade de aplicar vazão uniforme ao longo da linha lateral, sendo esta controlada em função da variação no comprimento dos microtubos. Entretanto se optou, nesta pesquisa, por utilizar um gotejador autocompensante inserido na linha lateral, para controlar a vazão de saída no tubo protetor, em função da praticidade em utilizar um medidor de vazão magnético nas avaliações de campo.

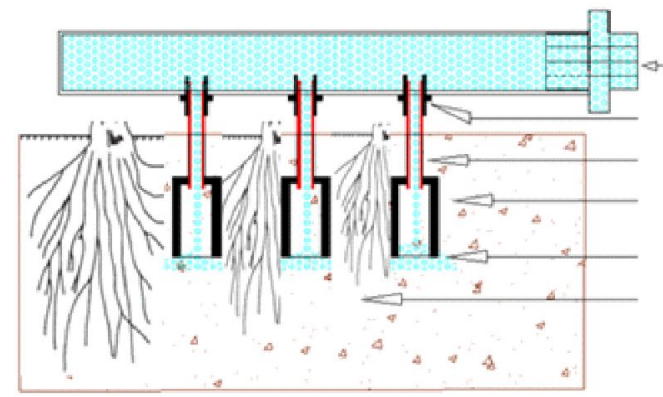

Entrada de água na lateral Conector Microtubo Tubo protetor Saida de água Solo com raizes

Figura 1. Ilustração das partes constituintes do emissor com proteção

O processo construtivo do sistema é simples e composto por um microtubo de polietileno com $4 \mathrm{~mm}$ de diâmetro interno e comprimento dependente da profundidade do sistema radicular da cultura, conectado a um gotejador de $2,0 \mathrm{~L} \mathrm{~h}^{-1}$ para controlar a vazão, instalado sobre a linha lateral, fazendo a ligação entre esta e o microtubo e pelo tubo protetor de 10-15 $\mathrm{cm}$ de comprimento (Figura 2), podendo ser de comprimento maior (preferencialmente). O tubo é vedado em uma das extremidades onde é furado para inserção do microtubo e, na outra extremidade, ocorre a saída da água; em seguida, o mesmo é colocado na vertical dentro do solo (Figuras 1 e 2). É importante lembrar que não deve haver solo, água nem nutrientes no interior do tubo. Portanto, embora neste trabalho a extremidade do tubo por onde a água sai tenha permanecido totalmente aberta, aconselha-se que esta tenha apenas um pequeno furo para saída de água, de modo a evitar a entrada de solo dentro do tubo e, em contrapartida, de raiz e partículas sólidas no emissor.

Na Figura 2 apresenta-se o sistema protetor pronto para ser instalado em campo.

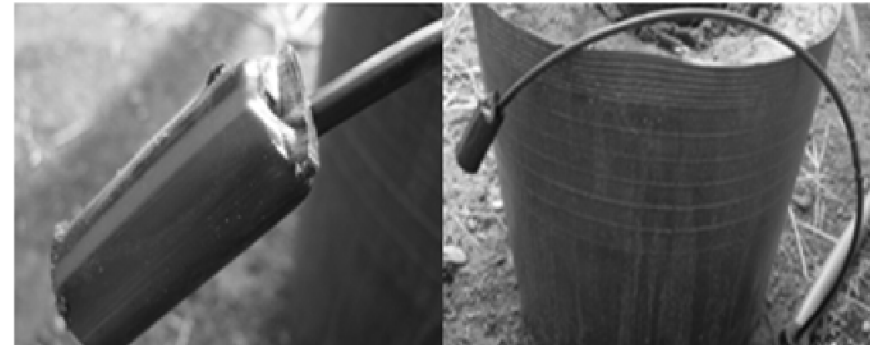

Figura 2. Protetor de emissor pronto para ser instalado em vaso

As avaliações de intrusão radicular e sucção de partículas sólidas também foram realizadas utilizando-se um gotejador convencional autocompensante comercializado para irrigação subsuperficial, com vazão nominal de $2,0 \mathrm{~L} \mathrm{~h}^{-1}$ (sistema B). Utilizando-se uma mangueira gotejadora de $13 \mathrm{~mm}$ cortaram-se partes de $20 \mathrm{~cm}$, contendo um orifício gotejador em cada uma, sendo tais partes vedadas nas extremidades e furados para inserção de um microtubo de $4 \mathrm{~mm}$ de diâmetro interno. $\mathrm{O}$ microtubo tem a função de interligar os emissores enterrados à linha lateral, facilitando no momento de medição da vazão com o medidor magnético.

Em laboratório avaliaram-se o coeficiente de variação de fabricação (CVF) do gotejador utilizado para controlar a vazão do modelo com protetor de emissor (modelo A) e o do gotejador convencional (modelo B). Para tanto, montou-se uma bancada contendo 50 emissores de cada modelo. O coeficiente de variação de fabricação se apresenta pela Eq. 1 .

$$
\mathrm{CVF}=\left(\frac{\mathrm{s}}{\mathrm{Q}_{\mathrm{m}}}\right)
$$

em que:

CVF - coeficiente de variação de fabricação, decimal

$\mathrm{s}$ - desvio padrão das vazões, $\mathrm{L} \mathrm{h}^{-1}$

$\mathrm{Q}_{\mathrm{m}}$ - vazão média, $\mathrm{L} \mathrm{h}^{-1}$

Na Tabela 1 se encontram as classificações dos coeficientes de variação de fabricação pela Associação Brasileira de Normas Técnicas, no projeto 12: 02.08-022 (ABNT, 1986) e por Solomon (1984).

Em casa de vegetação implantou-se um sistema de irrigação subsuperficial em ambiente protegido, para avaliação das

Tabela 1. Classificações para os coeficientes de variação de fabricação (CVF) pela ABNT (1986) e por Solomon (1984)

\begin{tabular}{lc}
\hline Valor do CVF (\%) & \multicolumn{1}{c}{ Classificação } \\
Até 10\% & ABNT (1986) \\
Entre 10\% e 20\% & Uniformidade boa \\
Entre 20\% e 30\% & Uniformidade média \\
Acima de30\% & Uniformidade marginal \\
& Uniformidade inaceitável \\
\hline Até 3\% & Solomon (1984) \\
Entre 4\% e 7\% & Uniformidade excelente \\
Entre $8 \%$ e 10\% & Uniformidade média \\
Entre 11\% e 14\% & Uniformidade marginal \\
CVF acima de15\% & Uniformidade ruim \\
& Uniformidade inaceitável \\
\hline
\end{tabular}


vazões nos emissores e, consequentemente, do seu entupimento, para o que se utilizaram o emissor convencional e o sistema com protetor do emissor, já descritos. A instalação ocorreu em 17 de julho de 2010 em vasos com $32 \mathrm{~cm}$ de profundidade por $30 \mathrm{~cm}$ de diâmetro, e volume de $0,020 \mathrm{~m}^{3}$, contendo cana-de-açúcar e sem cultura, para análise trimestral de entupimentos decorrentes da intrusão radicular e partículas sólidas do solo. Na Figura 3 apresenta-se o experimento instalado para avaliação, com os emissores colocados em vasos com e sem cultura.

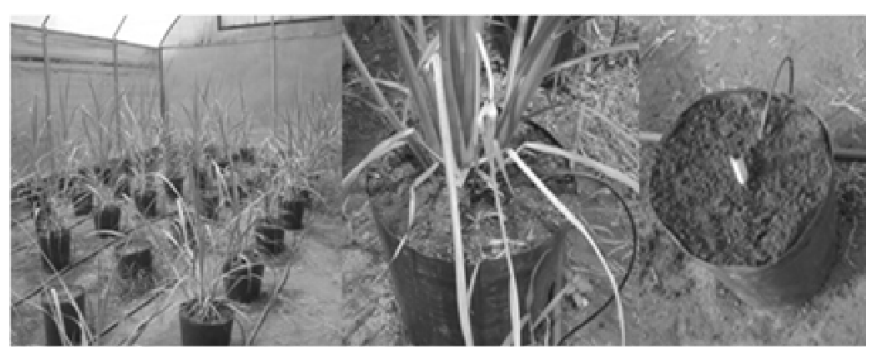

Figura 3. Instalação dos emissores em vasos com e sem cultura

Utilizou-se um sistema com motobomba para recalque da água, filtro de discos e manômetro instalados após a sucção. $\mathrm{O}$ experimento foi montado contendo linhas laterais com 10 emissores de cada modelo para os vasos com e sem cultura, instalados dentro do solo a $20 \mathrm{~cm}$ de profundidade. Utilizou-se cana-de-açúcar para avaliação do processo de intrusão de raiz, por se tratar de uma cultura que apresenta sistema radicular agressivo aos emissores. A variedade escolhida foi a RB867515, mais cultivada no Estado de São Paulo. O solo foi classificado como Latossolo Vermelho Amarelo, textura franco-argilosa, denominado Série Sertãozinho.

Nos vasos sem cana efetuaram-se tratos culturais monitorados de forma a não conter erva daninha, evitando-se a presença de raízes dentro do vaso e possibilitando avaliar o processo de entupimento por sucção de partículas sólidas de solo. A cana-de-açúcar (cana planta) foi cortada no décimo mês pois já havia atingido determinada altura não suportada pela estufa, embora o experimento tenha continuado com a avaliação.

O manejo de irrigação foi realizado com base na umidade do solo estimada pela curva de retenção de água, utilizando-se três tensiômetros em cada linha lateral (em três vasos distribuídos espaçadamente), mantendo-se o solo sempre com potencial hídrico próximo à capacidade de campo com tensão de sucção em torno de $5,0 \mathrm{kPa}$. O tempo de irrigação foi calculado para aplicação da lâmina de irrigação durante 8 min e intervalo entre irrigações de 3 e 4 dias, tempo este ajustado conforme as umidades obtidas na curva de tensão de água no solo, em função do valor médio das tensões lidas nos três tensiômetros instalados na linha lateral. O solo utilizado foi desestruturado para colocar nos vasos; portanto, os valores de tensão versus umidade não seguiram o mesmo padrão daqueles obtidos com solos em condições naturais de campo.

A curva de retenção foi construída simulando-se uma condição real de irrigação e evaporação em casa de vegetação. Utilizaram-se 3 vasos com capacidade de $12 \mathrm{~L}$, com orifícios na

parte inferior, contendo uma camada com $1 \mathrm{~cm}$ de brita $\mathrm{n}^{\circ} 1$, coberta com manta geotêxtil (BIDIM OP-30) e preenchidos com solo em camadas a cada $5 \mathrm{~cm}$ com massa e volume conhecido, a fim de se obter um solo com densidade conhecida. Nos vasos se instalaram tensiômetros a $0,15 \mathrm{~m}$ de profundidade. Os vasos foram imersos em água até metade da altura, para saturação lenta do solo, por ascensão capilar da água. Após a saturação os vasos foram cobertos com filme plástico, colocados para drenar naturalmente até finalizar o escoamento e, em seguida, determinou-se a capacidade máxima de retenção. Durante o processo de perda de água foram realizadas pesagens e leituras de tensão concomitantemente, até quando se verificou uma tensão de $100 \mathrm{kPa}$ (Figura 4). A equação potencial de umidade média do solo foi obtida pela curva de tensão versus umidade do solo (Figura 4), utilizada no manejo da irrigação.

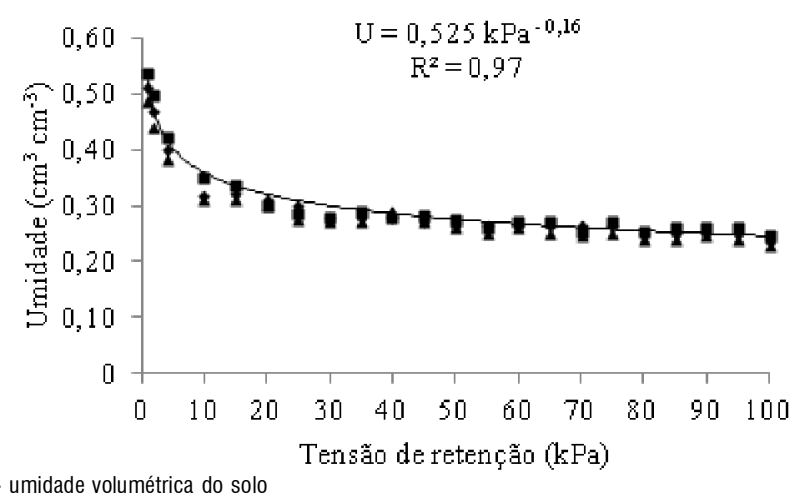

Figura 4. Curva de retenção da água do solo utilizado

Cada emissor foi monitorado periodicamente em relação às suas vazões, em vasos com e sem cultura. As vazões individuais dos emissores subsuperficiais foram determinadas utilizandose um medidor eletrônico, magnético indutivo, modelo IFC090-F, fabricado pela empresa Krohne/Conaut, capaz de medir vazões na faixa de 0 a $10 \mathrm{~L} \mathrm{~h}^{-1}$ (Figura 5), com possibilidade de erro de $0,3 \%$. Desta forma, tornou-se possível determinar as vazões desconectando-se o microtubo de abastecimento de cada gotejador, conectando-o ao medidor.

As análises se basearam nos dados das vazões temporais e ao longo da linha lateral, nos emissores instalados em vasos com e sem cultura, analisando-se a vazão inicial, quando se implantou a cultura da cana-de-açúcar e se enterraram os emissores, além das demais obtidas ao longo do período de avaliação.

A.

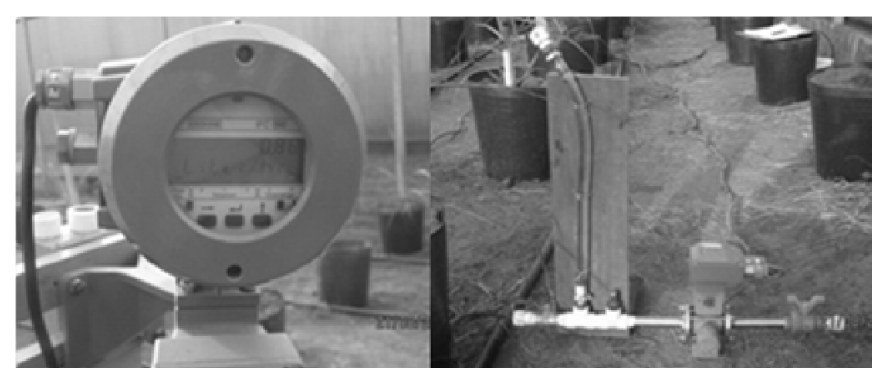

Figura 5. Medidor de vazão - leitor digital (A) e sensor magnético com conexões (B) 
A determinação das vazões foi realizada a cada três meses contados após a implantação do sistema de irrigação em 17 de julho de 2010, sendo realizada a última avaliação em 17 de julho de 2011, para este trabalho. Os valores obtidos foram utilizados para o cálculo da vazão relativa $\left(Q_{R}\right)$, indicando o quanto o valor do período posterior de análise representa sobre aquele medido no primeiro período, e do grau de entupimento dos emissores $\left(G_{E}\right)$ como indicativo do percentual de redução da vazão que pode ser ocasionado por entupimento ou outro fator. Além dessas avaliações analisaram-se as vazões obtidas nos sistemas com e sem cultura, por meio de um gráfico de "Box" (Boxplot) e se desmontaram os sistemas para análise visual de intrusão radicular e presença de solo dentro dos emissores. A vazão relativa foi determinada para cada emissor contido na linha lateral, calculando-se a vazão relativa média na lateral, para o que os valores médios da leitura posterior foram divididos pelos da leitura anterior. $O G_{E}$ e $Q_{R}$ são representados pelas Eqs. 2 e 3, respectivamente.

$$
\begin{gathered}
\mathrm{G}_{\mathrm{E}}=100\left(1-\frac{\mathrm{Q}_{1}}{\mathrm{Q}_{\mathrm{n}}}\right) \\
\mathrm{Q}_{\mathrm{R}}=\frac{\mathrm{Q}_{1}}{\mathrm{Q}_{\mathrm{n}}}
\end{gathered}
$$

em que:

$\mathrm{G}_{\mathrm{E}}$ - grau de entupimento dos emissores, \%

$\mathrm{Q}_{1}$ - vazão obtida nos emissores no período de testes anterior, $\mathrm{L} \mathrm{h}^{-1}$

$Q_{n}$ - vazão obtida nos emissores no enésimo período de testes, $\mathrm{L} \mathrm{h}^{-1}$

$$
Q_{R} \text { - vazão relativa, adimensional }
$$

Com base nos resultados da vazão coletada em cada período de análise foi possível avaliar a ocorrência ou não da intrusão radicular em emissores enterrados em vasos com cultura ou, ainda, sucção de partículas sólidas de solo em emissores instalados em vasos sem cultura. A avaliação final ocorreu com abertura dos vasos e corte transversal dos emissores para análise, 12 meses após a instalação.

Uma análise econômica simples, como forma de mostrar a importância de se buscar métodos alternativos em sistemas de irrigação localizada subsuperficial, foi realizada comparandose os custos de aquisição dos dois métodos utilizados nesta pesquisa (sistemas "B" e "A") utilizando-se, hipoteticamente, 1 emissor por planta. No sistema "A" apesar de se ter utilizado um gotejador, na prática ele não seria necessário, podendo ser substituído por um microtubo para controlar a vazão de saída no protetor de emissor uma vez que o gotejador somente foi utilizado para facilitar o trabalho (acoplar e desacoplar) de medir a vazão, conforme comentado no item sobre concepção do sistema "A"; além do mais, o microtubo pode ser utilizado em irrigação localizada obtendo-se uniformidade da vazão com variação do comprimento, conforme recomendado por Souza et al. (2011). Portanto, no sistema "A" consideraram-se o uso de um microtubo de $30 \mathrm{~cm}$ de comprimentoe $1,00 \mathrm{~mm}$ de diâmetro interno, um conector e $15 \mathrm{~cm}$ de mangueira de polietileno para servir de protetor da saída do microtubo. No sistema "B" contabilizou-se o custo de $20 \mathrm{~cm}$ de mangueira gotejadora contendo um gotejador convencional para irrigação subsuperficial por gotejamento.

\section{RESULTADOS E DISCUSSÃO}

De acordo com os resultados de laboratório obtidos nas avaliações do coeficiente de variação de fabricação (CVF) para cada modelo de emissor utilizado na pesquisa, os emissores utilizados nos sistemas "A" (sistema de gotejamento com protetor do emissor) e "B" (gotejador convencional para irrigação subsuperficial) apresentaram CVF iguais a 2,93 e 2,87, respectivamente. Verifica-se que foi possível obter CVF com as melhores classificações pela ABNT (1986) e Solomon (1984). Desta forma, a uniformidade de aplicação da água não será afetada significativamente pela variação de fabricação dos emissores e sim pela provável variação na vazão, devido ao entupimento (por raiz e/ou partículas sólidas).

Nas Figuras 6 e 7 se apresentam, graficamente, pelo Boxplot, os dados de vazão coletados no sistema protetor com gotejador para controlar a vazão (A), instalado em vasos com cultura (SAC) e apenas com solo (SAS) e no gotejador convencional para irrigação subsuperficial (B), em vasos com cultura (SBC) e apenas com solo (SBS), avaliados trimestralmente.

Conforme o gráfico da Figura 6, no sistema "A" com cultura (SAC) e sem cultura (SAS), não houve redução na vazão dos

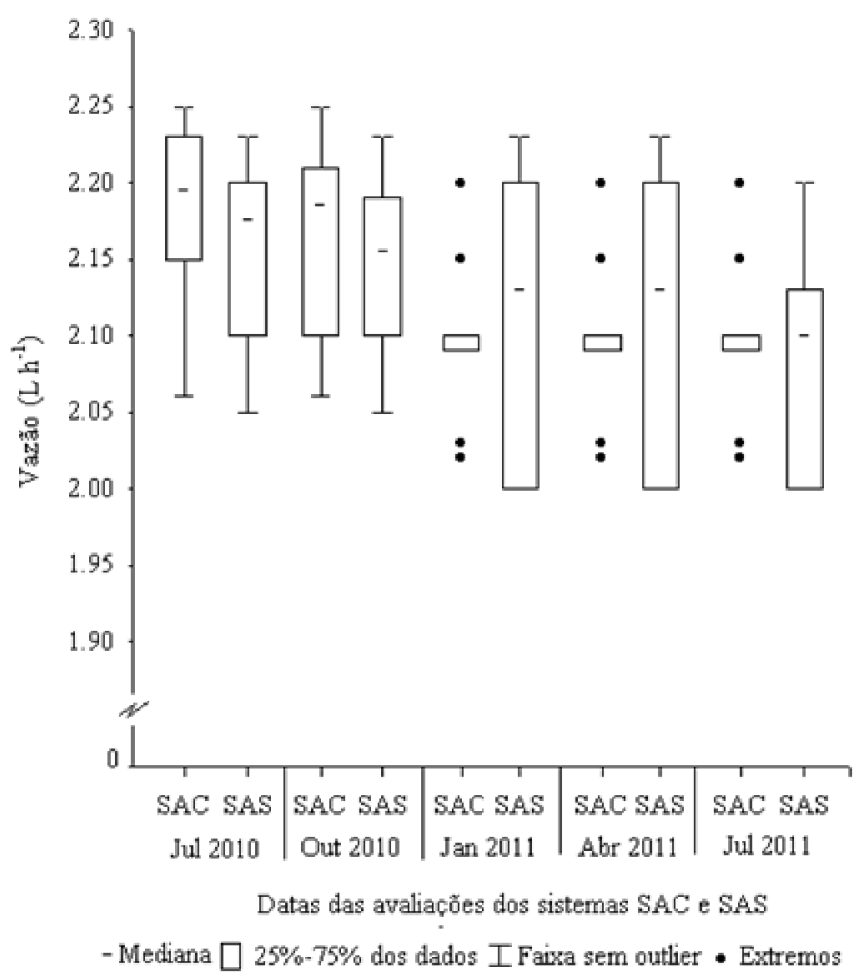

Figura 6. Boxplot para o sistema " $A$ " em vasos com cana (SAC) e sistema " $A$ " em vasos com solo (SAS), para as diferentes datas de avaliação 


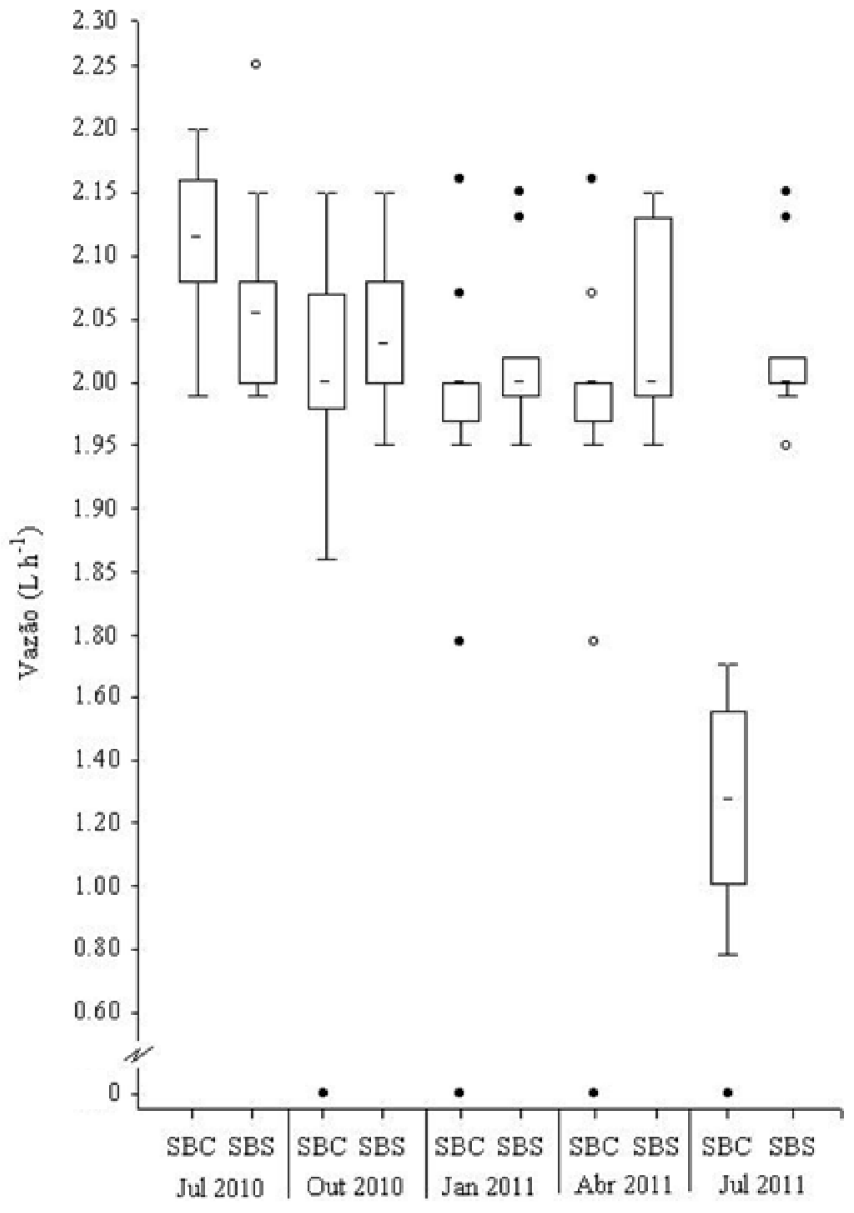

Datas das avaliacốes dos sistemas SBC e SBS

- Mediana $\square 25 \%$ - $75 \%$ dos dados I Faixa sem outlier • Extremos a Outliers Figura 7. Boxplot dos dados de vazão para o sistema "B" em vasos com cana (SBC) e sistema "B" em vasos com solo (SBS), para as diferentes datas de avaliação

emissores, tendo-se pequenas variações temporais, de julho de 2010 (data da instalação) a julho de 2011, com valores oscilando em torno de $2,0 \mathrm{~L} \mathrm{~h}^{-1}$. As pequenas variações não caracterizaram entupimento, uma vez que elas podem ocorrer pela oscilação esperada em virtude da precisão do medidor eletrônico de vazão, com possibilidade de erro passível ocorrer até mesmo por oscilação da frequência de energia na rede elétrica. Observa-se que os valores máximos e mínimos estiveram próximos da mediana e do primeiro e terceiro quartis, havendo pouca oscilação nos dados. Os valores de mediana estiveram acima de 2,0 $\mathrm{L} \mathrm{h}^{-1}$, no SAC e no SAS. Nota-se pouca variação dos dados entre esses quartis, cuja ocorrência é devida à pequena oscilação na medição ao longo da linha lateral, justificada pelo coeficiente de variação de fabricação dos emissores, apresentado anteriormente. Nas avaliações realizadas para o SAC nos três últimos trimestres, apesar dos valores extremos (além da faixa onde poderia haver outliers), eles se mantiveram entre 2,0 e $2,20 \mathrm{~L} \mathrm{~h}^{-1}$, estando os dados entre o primeiro e o terceiro quartil, concentrados em torno de $2,10 \mathrm{~L} \mathrm{~h}^{-1}$, valor este similar àqueles obtidos na primeira avaliação (julho de 2010).

Pelo gráfico da Figura 7 nota-se ocorrência de outliers e dados extremos com valores iguais a zero quando ocorreu intrusão radicular, obstruindo totalmente o emissor. Tal como para o sistema "A", no sistema "B" também ocorreram pequenas variações da vazão ao longo do tempo de avaliação tanto no SBC quanto no SBS. No último período de avaliação do SBC nota-se que, apesar de a mediana se localizar próxima ao centro entre o primeiro e terceiro quartil, houve grande variação dos dados de vazão, evento devido à intrusão radicular em todos os emissores, causando entupimento total de alguns, bem como pela redução na vazão de todos, ao longo da linha lateral, conforme pode ser visto na Tabela 2 . Por outro lado, nos vasos sem cultura a vazão se manteve com pequena variação temporal mas com valores próximos durante todo o período avaliado, sem entupimento por sucção de partículas sólidas de solo. No último período, para o SBC não se observou outlier em virtude da grande variação dos dados verificada pela extensa faixa limite entre o primeiro e o terceiro quartil.

Tabela 2. Vazões relativas médias $\left(Q_{\text {média }}\right)$ na linha lateral e coeficiente de variação da vazão relativa (CVQR) nos diferentes sistemas de avaliação

\begin{tabular}{ccccc}
\hline Data da & \multicolumn{5}{c}{ Sistemas utilizados } \\
\cline { 2 - 5 } avaliação & SAC & \multicolumn{2}{c}{ SAS } & \multicolumn{1}{c}{ SBC } \\
QR & SBS \\
Out 2010 & 0,99 Aa & 1,00 Aa & $0,86 \mathrm{Aa}$ & $0,99 \mathrm{Aa}$ \\
Jan 2011 & $0,96 \mathrm{Aa}$ & $0,98 \mathrm{Aa}$ & $0,85 \mathrm{Aa}$ & $0,97 \mathrm{Aa}$ \\
Abr 2011 & $0,96 \mathrm{Aa}$ & $0,98 \mathrm{Aa}$ & $0,85 \mathrm{Aa}$ & $0,97 \mathrm{Aa}$ \\
Jul 2011 & $0,96 \mathrm{Aa}$ & $0,97 \mathrm{Aa}$ & $0,51 \mathrm{Bb}$ & $0,98 \mathrm{Aa}$ \\
\hline \multicolumn{5}{c}{$\mathrm{CVQR}(\%)$} \\
Out 2010 & 2,50 & 4,93 & 35,59 \\
Jan 2011 & 2,84 & 6,38 & 35,49 & 2,91 \\
Abr 2011 & 2,84 & 6,38 & 35,49 & 1,68 \\
Jul 2011 & 2,84 & 4,64 & 58,21 & 1,66 \\
\hline
\end{tabular}

Médias seguidas de mesma letra, maiúscula na coluna e minúscula na linha, não diferem entre si por Tukey a $1 \%$

SAC - sistema A com cana; SAS - sistema A com solo; SBC - sistema B com cana; SBS - sistema B com solo

$\mathrm{Na}$ Tabela 2 se apresentam as vazões relativas médias $\left(\mathrm{QR}_{\text {média }}\right)$ na linha lateral de irrigação e o coeficiente de variação da vazão relativa (CVQR), avaliados ao longo do tempo, trimestralmente, com a primeira medição em 17 de julho de 2010, para o sistema "A" com cana (SAC), sistema "A" com solo (SAS), sistema "B" com cana (SBC), e sistema "B" com solo (SBS).

Pela Tabela 2 nota-se que as vazões relativas médias estiveram próximas da unidade na maioria dos emissores, um pouco aquém. Para os SAC, SAS e SBS, os valores de $\mathrm{QR}_{\text {média }}$ foram maiores ou iguais a 0,96 , indicando que a vazão medida ao longo do tempo de avaliação foi bem próxima da vazão inicial, não ocorrendo sua redução por raiz ou partículas sólidas de solo. $\mathrm{A} \mathrm{QR}_{\text {média }}$ do sistema SBC foi menor ou igual a $0,86 \mathrm{em}$ todas as datas de avaliação, mantendo-se com valores próximos ao mencionado, até o terceiro trimestre (abril de 2011). No quarto e último trimestre, o SBC apresentou redução acentuada da $\mathrm{QR}_{\text {média, }}$ apresentando valor igual a 0,51 , sendo estatisticamente a menor dentre os sistemas e os trimestres avaliados, tendo CVQR muito alto, devido à variabilidade dos dados, conforme visto no gráfico da Figura 7. No último período prevaleceu entupimento total dos emissores no SBC, assim como foi encontrado por Coelho et al. (2007), para partículas 
sólidas na malha hidráulica. Nos SAC, SAS e SBS, os valores de vazão relativa não se diferenciaram estatisticamente pelo teste Tukey a 0,01 de probabilidade. Os dados de CVQR para o SAC e SBS atingiram as melhores classificações, conforme Solomon (1984) e ABNT (1986), enquanto para o SAS se obteve classificação média por Solomon e boa pela ABNT, durante todos os trimestres de avaliação. Por outro lado, para o SBC os valores de CVQR foram considerados inaceitáveis por Solomon (1984) e pela ABNT (1986) em todos os trimestres de avaliação.

$\mathrm{Na}$ Figura 8 se encontram os resultados das avaliações do grau de entupimento $\left(\mathrm{G}_{\mathrm{E}}\right)$ médio, para o sistema "A" com cana (SAC), sistema "A" com solo (SAS), sistema "B" com cana (SBC) e sistema "B" com solo (SBS), tendo-se como base as vazões da primeira medição (17 de julho de 2010) e aquelas obtidas a cada três meses.

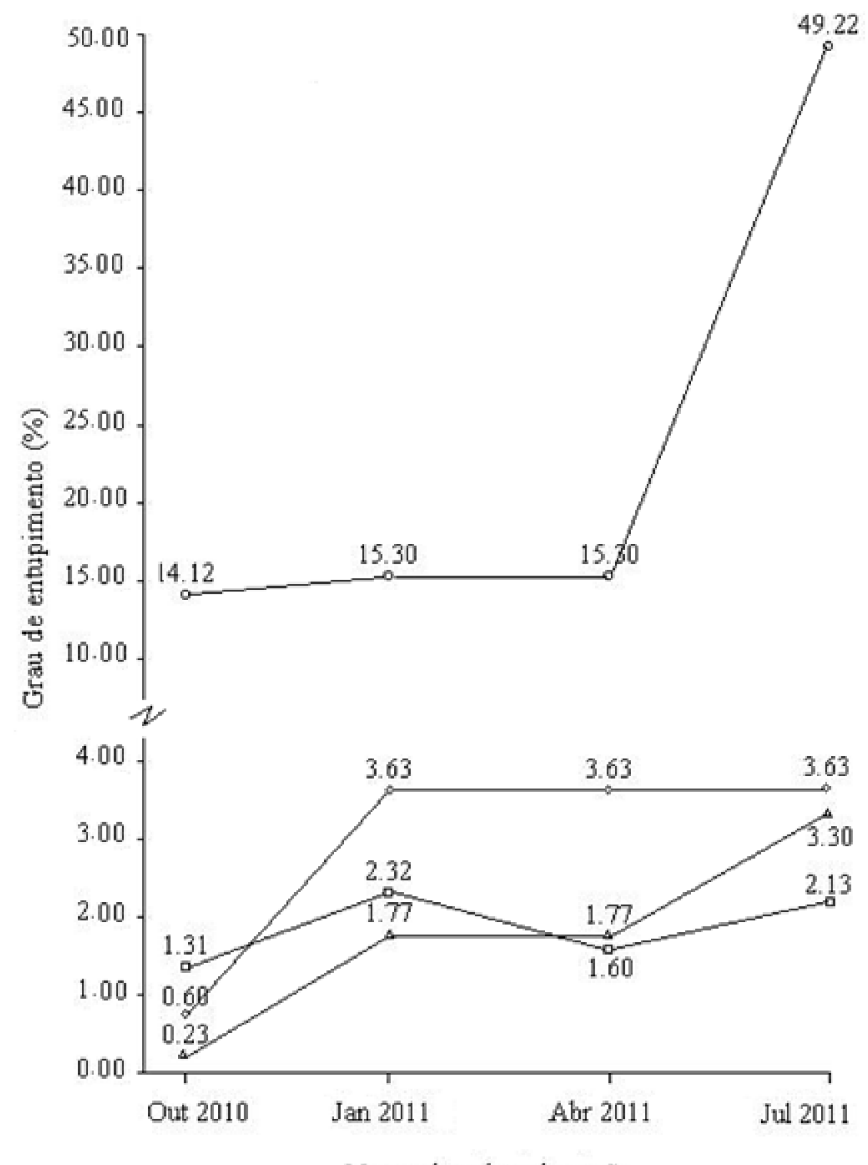

Meses de coleta da vazã̃o

$=\mathrm{SBC} \rightarrow \mathrm{SBS} \rightarrow \mathrm{SAC} \rightarrow \mathrm{SAS}$

Figura 8. Grau de entupimento médio obtido em cada sistema com solo e cana, determinados trimestralmente de julho de 2010 a julho de 2011

Pela Figura 8 nota-se, para SAC, SAS e SBS, que o grau de entupimento $\left(\mathrm{G}_{\mathrm{E}}\right)$ foi baixo, com valores menores ou iguais a $3,30 \%$ em todos os períodos de avaliação. Este valor não indica entupimento por raiz ou partículas sólidas de solo visto que, conforme já comentado, pode ocorrer pequena variação na leitura da vazão com o medidor magnético. Por outro lado, no SBC o $\mathrm{G}_{\mathrm{E}}$ teve valor alto $(14,12 \%)$ já no primeiro período de avaliação (três meses após implantação do sistema), devido sobretudo ao

entupimento total de um emissor, mantendo-se com valor próximo ao mencionado até a terceira avaliação (abril de 2011). Na quarta avaliação, realizada em julho de 2011, ocorreu outro emissor totalmente entupido e os demais tiveram as vazões reduzidas; com isto, o de $G_{E}$ aumentou para 49,22\%. O alto valor de $G_{E}$ na última avaliação é confirmado pela ocorrência dos baixos valores de $Q_{R}$ média, verificados na Tabela 2 .

Observam-se, em um corte transversal realizado nos emissores, seus aspectos finais em relação à entrada de partículas sólidas de solo e raiz, para os SAS, SAC, SBS e SBC nas Figuras 9A, 9B, 9C e 9D, respectivamente.

A.

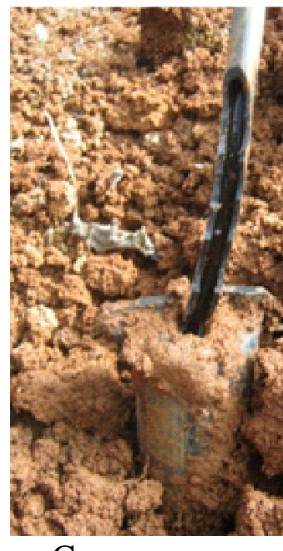

C.

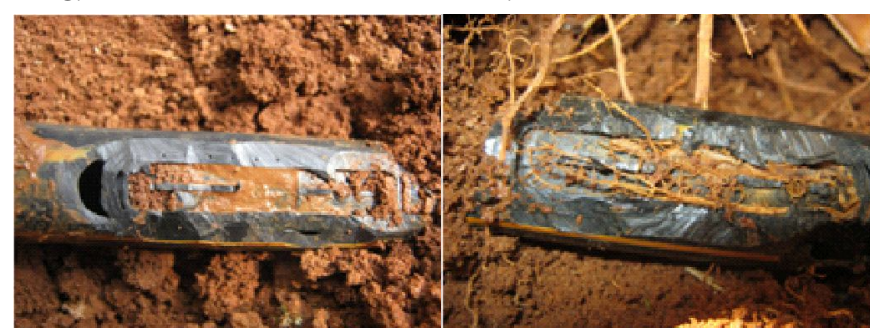

Figura 9. Aspectos finais dos emissores em relação à entrada de partículas sólidas de solo e raiz, para o sistema A com solo (SAS) (A), com cana (SAC) (B), sistema B com solo (SBS) (C) e com cana (SBC) (D)

Observam-se resultados condizentes com os valores de $\mathrm{QR}_{\text {média }}$ e GE apresentados na Tabela 2 e na Figura 8, respectivamente. Nos SAS e SAC não ocorreu entrada de solo e intrusão por raiz, enquanto no SBS há presença de solo dentro do emissor, indicando sucção das partículas sólidas; entretanto, a quantidade de solo observada no SBS ainda não foi suficiente para causar entupimento, conforme constatado pelos valores de $G_{E}$ e $Q_{R}$. No SBC observou-e grande quantidade de raiz dentro do emissor, capaz de causar entupimento o que contribuiu, sobremaneira, para redução da vazão relativa, além de aumento do grau de entupimento, tendo-se alguns emissores deste sistema totalmente entupidos.

No período de avaliação, em que o solo foi mantido com umidade próxima à capacidade de campo, os emissores com protetor não apresentaram entupimento enquanto os gotejadores convencionais entupiram, confirmando a hipótese apresentada em um trabalho realizado por Coelho et al. (2006) com variação de vazão em gotejadores convencionais, em que 
os autores concluíram que o sistema radicular de plantas bem irrigadas apresentou notável vigor, podendo ser bastante agressivo a este tipo de emissor.

Na Tabela 3 se acham os materiais utilizados para o sistema com protetor (A) e gotejador convencional (B), relacionados aos custos para cada sistema, considerando-se hipoteticamente 1 emissor por planta, com valores obtidos em agosto de 2011.

Tabela 3. Materiais utilizados para o sistema com protetor (A) e gotejador convencional (B) e custos para cada sistema

\begin{tabular}{|c|c|c|c|}
\hline \multicolumn{2}{|c|}{ Sistema (A) } & \multicolumn{2}{|c|}{ Sistema (B) } \\
\hline Materiais & $\begin{array}{c}\text { Custo } \\
\left(\mathrm{R}^{* *}\right)\end{array}$ & Materiais & $\begin{array}{c}\text { Custo } \\
\left(\mathrm{R} \${ }^{* *}\right)\end{array}$ \\
\hline $0,30 \mathrm{~m}$ de microtubo & 0,05 & & \\
\hline 1 conector & 0,05 & Tubo com gotejador & $0,32^{*}$ \\
\hline $0,15 \mathrm{~m}$ de mangueira & 0,09 & & \\
\hline Total & 0,19 & Total & 0,32 \\
\hline
\end{tabular}

* custo para cada gotejador autocompensante com vazão de $2,0 \mathrm{~L} \mathrm{~h}^{-1}$, considerando-se tubos com 4 gotejadores por metro linear

** custo do dólar $=\mathrm{R} \$ 1,66$

A literatura carece de trabalhos que apontem a viabilidade econômica comparativa entre tipos de gotejadores. Holzapfel et al. (2007) fizeram uma avaliação técnico-econômica para gotejadores compensantes e não compensantes, com diferentes vazões, considerando os custos fixos e variáveis, não sendo analisado o fator entupimento. Nos resultados obtidos os emissores não compensantes de pressão apresentaram menor custo total anualizado em relação aos compensantes devido ao fator redutor de custo na aquisição e menor faixa de pressão de operação utilizada nos emissores não compensantes. Ainda de acordo com os autores, emissores com vida útil maior que 7 anos, são desejáveis. Nesta pesquisa se compara o uso de um método alternativo de irrigação por gotejamento com um sistema convencional compensante, analisando-se apenas os custos de aquisição dos emissores. Nota-se, pela Tabela 3, que o sistema alternativo "A" apresentou custo bastante reduzido, aproximadamente $59 \%$ do valor do sistema convencional "B"; entretanto, o sistema "A" ainda é de instalação manual, o que dificulta seu uso em grandes áreas; por outro lado, para pequenas áreas pode ser utilizado principalmente em culturas arbóreas ou em vasos. Apesar da dificuldade de instalação do sistema "A", deve-se ponderar, sobremaneira, o fato de que no sistema "B" há redução nos valores das vazões relativas (Tabela 2) e aumento do grau de entupimento (Figura 8) dos emissores.

\section{CONClusÕES}

1. O sistema com o gotejador convencional em vasos sem cultura (SBS) não apresentou redução significativa da vazão durante um ano de uso enquanto o sistema com cultura (SBC) sinalizou entupimento por raiz, não sendo indicado para uso em irrigação por gotejamento subsuperficial, nas condições analisadas nesta pesquisa.

2. O sistema com protetor de emissor foi efetivo em evitar a entrada de raiz e partículas sólidas de solo nas condições desta pesquisa, durante o período avaliado.
3. O sistema alternativo com protetor apresentou menor custo para aquisição dos emissores.

\section{AgRADECIMENTOS}

Os autores agradecem ao Ministério da Ciência e Tecnologia (MCT) e à Fundação de Amparo à Pesquisa do Estado de São Paulo (FAPESP), pelo apoio financeiro a esta pesquisa, através do Instituto Nacional de Ciência e Tecnologia em Engenharia da Irrigação (INCTEI).

\section{LITERATURA CITADA}

ABNT - Associação Brasileira de Normas Técnicas. Requisitos mínimos para elaboração de projetos de sistema de irrigação localizada. São Paulo: ABNT, 1986.18p.

Cloi, C. Y.; Suarez-Rey, E. M. Subsurface drip irrigation for bermudagrass with reclaimed water. Transactions American Society of Agricultural Engineers, v.47, p.1943-1951, 2004.

Coelho, R. D.; Faria, L. F.; Mélo, R. F. Variação de vazão em gotejadores convencionais enterrados por intrusão radicular na irrigação de citros. Irriga, v.11, p.230-245, 2006.

Coelho, R. D.; Vilela, L. A. A.; Resende, R. S.; Teixeira, M. B.; Sá, J. S. De. Entupimento de gotejadores em decorrência de pulsos de partículas sólidas na malha hidráulica. Irriga, v.12, p.108-122, 2007.

Gil, M.; Sinobas, R.; Juana, L.; Sáchez, R.; Losada, A. Emitter discharge variability of subsurface drip irrigation in uniform soils: Effect on water-application uniformity. Irrigation Science, v.26, p.451-458, 2008.

Holzapfel, E. A.; Abarca, W. A.; Paz, V. P. da S.; Arumi, J. L.; Rodriguez, A.; Orrego, X.; Lopez, M. A. Selección técnicoeconomica de emisores. Revista Brasileira de Engenharia Agrícola e Ambiental, v.11, p.547-556, 2007.

Marques, P. A. A.; Frizzone, J. A.; Teixeira, M. B. O estado da arte da SDI. Colloquium Agrarian, v.2, p.17-31, 2006.

May, D.; Hanson, B. The effect of drip line placement on yield and quality of drip-irrigated processing tomatoes. Irrigation and Drainage System, v.21, p.109-118, 2007.

Mosca, M. A.; Testezlaf, R.; Gomes, E. P. Desenvolvimento de emissores alternativos para irrigação subsuperficial de baixa pressão. Irriga, v.10, p.249-262, 2005.

Parkes, M.; Yao, W. W.; Ma, X. Y.; Li, J. Simulation of point source wetting pattern of subsurface drip irrigation. Irrigation Science, v.29, p.331-339, 2010.

Rajput, T. B. S.; Patel, N. Effect of subsurface drip irrigation on onion yield. Irrigation Science, v.27, p.97-108, 2009.

Resende, R. S.; Coelho, R. D.; LeaL, M. L. da Silva.; Mata, S. S. da. Susceptibilidade à intrusão radicular de gotejadores convencionais na irrigação subsuperficial de cana-deaçúcar. Irriga, v.9, p.150-165, 2004.

Singh, D. K.; Rajput, T. B. S.; Sikarwar, H. S.; Sahoo, R. N.; Ahmed, T. Simulation of soil wetting pattern with subsurface drip irrigation from line source. Agriculture Water Management, v.83, p.130-134, 2006. 
Solomon, K. H. Yield related interpretations of irrigation uniformity and efficiency measures. Irrigation Science, v.5, p.161-172, 1984.

Souza, W. J.; BotreL, T. A.; Carvalho, D. F. de.; Silva, L. D. B. da. Fertigação em mudas de citros utilizando-se mangueiras e microtubos sob regime de escoamento turbulento. Brasileira de Engenharia Agrícola e Ambiental, v.15, p.816-822, 2011.
Suarez-Rey, E. M.; Choi, C. Y.; McCloskey, W. B.; Kopec, D. M. Effects of chemicals on root intrusion into subsurface drip emitters. Irrigation and Drainage, v.55, p.501-509, 2006.

Tabatabaei, S. H.; Najafi, P. Effect of using subsurface drip irrigation and ET-HS model to increase WUE in irrigation of some crops. Irrigation and Drainage, v.56, p.477-486, 2007. 